\title{
La nueva religión del imperio corporal y las energías espirituales de la educación popular
}

The new religion of the body kingdom and the spiritual power of the popular education

\section{Dairo Elias González Quiroz"*}

\begin{abstract}
“...No hace mucho tiempo, la mujer debia tener tetas grandes, cadera florentina, labios húmedos. El cine y la TV empujaron esa imagen, y las mujeres y, sobre todo, los hombres, la adoptamos" ( Perchas de Alfredo Molano B.) con el lema "tetas y colas matan neuronas" porque "sin tetas ni colas no hay paraiso". Pero hoy la imagen ideal es la mujer habichuela: labios henchidos de deseos, calzones de los que casi se desprende el olor, larga y flaca y voluptuosa sólo ahi en donde te imaginas. Y para mañana será comprensible que aparezca "la generación de las multiorgásmicas", que encierra a mujeres "vendedoras de su propio yo (sexo ventiao), desnudas de conceptos porque hablan con frases hechas que saben explosivas, que saben escandalosas" (Las multiorgásmicas de Héctor Rincón). "Señor, si no puedes hacerme adelgazar, haz que engorden todas mis amigas" (Anónimo). ¡Espejito, espejito!: ¿quién es la más bonita?... ¡Ah!, ¡qué espejo tan embustero! (Combinación impopular de dichos populares). "Hay muchos modos de ocuparse de la belleza. Para unos es ocasión de lucro, para otros, de vanidad. Intentan unos poseerla, otros, producirla. Y un quehacer más noble, inocente e inútil es tratar sólo de teorizar acerca de ella" (Abelardo Lobato).
\end{abstract}

\section{A guisa de exordio}

El desarrollo de la investigación lingüística, los avances de las tecnologías y la dinámica de los estudios literarios han demostrado el predominio y la importancia de la comunicación y la información como el fundamento explicativo de todas las cosas que constituyen y revelan nuestro mundo. Por tanto, cualquier análisis del mundo será incompleto si no se aborda de manera prioritaria el conocimiento de éstas, ya que ellas atraviesan diversos ámbitos de la humanidad, la cultura y la sociedad y con mucha más razón el conocimiento, las relaciones de poder y la educación que se dan en la escuela, el colegio y la universidad. Es lógico pensar, entonces, que en un tercer semestre del Proyecto Curricular denominado Licenciatura de Educación Física (PC-LEF) no pueda prescindirse de un panel como el que nos convoca: el que ha de posibilitar el avance de los constructos fundamentales para comprender la comunicación y la información y encontrar sus relaciones con las experiencias corporales y la pedagogía, asunto clave en una tendencia curricular integrada e interdisciplinar que pretende redimensionar su concepción disciplinar en el ámbito de la educación.

Con el deseo de continuar aportando a la construcción de un PC-LEF sólido alrededor del cuerpo, la comunicación y la información, someto a discusión los tres imaginarios globales dominantes que he logrado aislar para con ellos examinar sus conexiones de época que tocan la producción estética actual: los miedos, los cuerpos, los medios masivos de información. "Si el miedo nos ubica en la sensación más cruda y repetida en varios recintos mentales de las industrias culturales, el cuerpo aparece como el más anhelado objeto del deseo representado tanto en modos de agresión y exclusión como por ser moldeador de lo deseante y liberador" (Silva, 2004, 9). Los mass media, por su parte, pueden entenderse "como el lugar mismo donde se da... la

Este escrito se llevó a cabo dentro del Proyecto Curricular Licenciatura en Educación Física, ciclo 1: Fundamentación del área pedagógica, en el taller de lenguaje del tercer semestre en el segundo período académico de 2005.

** Profesor de Taller Lenguajes de la Universidad Pedagógica Nacional y de Español y Literatura del Colegio Distrital José Asunción Silva. 
urbanización del planeta, en el paso hacia la máquina informática y biológica y el lugar donde se produce la tecnología comunicativa que renueva sensibilidades" (Ibid). En consecuencia el orden de mi reflexión es: primero, la introducción que ubica el porqué del mismo y su propósito; segundo, la nueva religión y los medios masivos de información; y tercero, comunicación, cultura y educación popular.

\section{La nueva religión y los medios masivos de información}

La belleza compensa la falta de educación; la inteligencia, la falta de atractivo físico; la riqueza, la falta de inteligencia y asi hasta el infinito.

Vance Pachard

Detrás de tus pensamientos y sentimientos, hermano mío, hay un amo más poderoso, un guia desconocido, se llama "uno mismo". Habita en tu cuerpo; es tu cuerpo. Federico Nietzsche

¡Que no sea tu cuerpo la primera sepultura de tu esqueleto!

I. Giraudux

Tu cuerpo es tu amigo, no lo trates como a un enemigo.

Anónimo

El entendimiento del cuerpo humano ha atravesado por miles de filosofías que lo alaban y lo desdeñan: antiguamente el cuerpo se asociaba con valores del comportamiento y era concebido como un medio y no como el fin de la realización personal. El templo del alma servía para enfatizar la "belleza interior" y su existencia era coyuntural y estática. Para Platón, el cuerpo era la prisión del alma inmortal; mientras que Epicuro lo defendió como única entidad posible, objeto receptor y emisor de placer, que no puede defenderse del espíritu. "El siglo veinte, con el desarrollo y la publicidad, democratizó la belleza corporal, como antes lo había hecho la religión con la belleza moral o espiritual" (Fernández, 2005, 1-3). Nuestra época carece de una idea dominante de cuerpo y en su ausencia, los medios de comunicación de masas han llenado ese vacío con el arte del consumo, caracterizado por un sincretismo total que, a juicio de Umberto Eco (2005), constituye un imparable politeísmo de la belleza. Este prototipo de belleza difundido de manera masiva se ha convertido en el signo de la sociedad occidental. "Las industrias textil y de cosméticos, la industria farmacéutica y las agencias de publicidad están obsesionadas con la explotación de una nueva mercancía que, aunque no se descubrió precisamente ayer, mueve hoy enormes ganancias: el cuerpo humano. No se trata de la esclavitud con cadenas y látigos aunque, de cierta forma, tiene la misma lógica” (Molano Bravo, 2004, 16A).
El cuerpo se ha transformado en mercancía y como tal está sometido a las reglas del mercado. Es el cuerpo de la ingeniería genética y la cirugía estética. Los programas televisivos Cambio Extremo en Colombia y Extreme Makeover en Estados Unidos son dos casos paradigmáticos de ello. Incluso, se está investigando la sustancia que reduce el crecimiento muscular y "se están desarrollando terapias genéticas que bloquearán la miostatina en seres humanos, y ofrecen inmensas promesas para tratar la distrofia muscular y la fragilidad que llega con el envejecimiento... La figura humana básica se volvería diferente, y cualquiera que tenga dinero podría tener la apariencia de un físico-culturista" (Kristof, 2004, 12A).

Es que no sólo son las modelitos en trance de preguntarle a jespejito, espejito!: ¿quién es la más bonita?; no sólo son ellas ni son sólo los modelos musculosos o tetones los que acuden todos los días al ritual de las estéticas para pulir sus curvas, sino que en este reinado del cuerpo entran todos: esos, los de siempre, y los que nunca habian ingresado al culto; "el quirófano televisivo muestra que es posible hacer realidad la fábula de convertir el sapo feo en príncipe, gracias al bisturí" (Fernández, $O p$. cit.) o la silicona que se ha transformado en productos de consumo masivo, prendas permanente de esa publicidad "que no busca engañar la razón, sino confundir el instinto" (Gaviria, 2005, 17A). El cuerpo como mercancia "predispone al sujeto a enfatizar la rentabilidad de la belleza y la imagen como capital social: se es la imagen del cuerpo que se tiene" (Fernández, Op. cit.), aunque ya lo había advertido el gran F. Niestzsche: "Nada es bello, sólo el hombre es bello; nada es feo, salvo el hombre que degenera".

Sabemos que la cirugía para reconstruir fisonomías se conoce desde la Antigüedad. Empezó con ocasión de las guerras, para readaptar soldados y civiles con lesiones deformantes. "A mediados de los 80 la demanda de intervenciones cosméticas se elevó como consecuencia, entre otras cosas, del incremento en la confianza en la cirugía general. Pero esencialmente porque los medios han exagerado su inocuidad, desviando su finalidad terapéutica y la frivolización relacionándola socialmente con el glamour y el dinero" (Ibid). Para "el estiércol del Diablo" no hay barreras de ningún tipo, y menos si se trata de las normas morales, en cuyas creación y destrucción las élites de los imperios basan sus negocios.

Estoy aterrado porque el negocio del cuerpo supera ampliamente las alarmas del obsesivo culto al bisturí televisivo: por más duro y escalofriante que sea, los cambios extremos nacionales e internacionales han impuesto un interés descomunal por la belleza física y un anhelo cada vez más generalizado por ser bellos, así se termine con un rostro de rasgos extraños como 
el de Michael Jackson. Ojalá no suceda lo mismo con uno de los jugadores de fútbol más populares que ha tenido el país, pero su melena larga y alborotada, sus lunares faciales y muchas de las características físicas que lo acompañaron a la fama van a desaparecer. Como se sabe, René Higuita aceptó participar en el programa Cambio Extremo por una jugosa suma de dinero. Hoy, cuando todos los parámetros de belleza deportiva apuntan a David Beckham, habrá que ver cómo resulta este experimento extremo nacional, que es un reto más difícil que tapar un disparo al arco haciendo la maniobra del escorpión.

Estoy atafagado porque el negocio del cuerpo supera ampliamente las alarmas del obsesivo culto a la delgadez extrema que ha llevado a miles de jóvenes colombianos a caer presas de la anorexia y de la bulimia, en la que se concentraron las preocupaciones desde hace mucho por las princesas y proletarias muertas. Anorexia y bulimia son enfermedades de los llamados trastornos de la conducta alimentaria, en las que el paciente tiene de sí mismo una imagen corporal negativa, se obsesiona por el peso y convierte en epicentro de su vida la adquisición de una silueta a tono con sus delirios.

Y es que, según datos de El Tiempo (2005, 1-22), en Colombia los pocos estudios que se han realizado respecto a estas enfermedades arrojan el preocupante dato de que nuestros índices de mujeres jóvenes entre los 14 y los 22 años que los padecen son significativamente mayores que los de los países desarrollados.

Esta nueva religión la han inventado los medios masivos de información para revolcarse a toda costa en el estiércol del diablo y lograr el reconocimiento de los otros a través de la diferencia con los otros, y es tan religión que eso es posible lograrlo, pero a partir de sacrificio: es posible que logremos el cielo y alcancemos la dicha eterna si nos sacrificamos bastante en esta vida para merecer la otra. En esta nueva religión del cuerpo "hay un miedo latente a todo, a no estar a la altura que la sociedad impone, $\mathrm{y}$ entonces se echa mano de la búsqueda de la belleza para exorcizar los miedos.

Una obstinación que llega a lo grotesco porque no otra cosa es esa pelea contra uno mismo que se manifiesta en cambiarse piezas del cuerpo para parecerse a otros, al estereotipo de la belleza que venden, pero como nunca podrás ser el otro siempre estarás lejos de lo que persigues y cada vez más lejos de lo que fuiste" (Rincón, 2005, 88).

Esa insatisfacción corporal es convertida por los medios masivos de información, como ya dijimos, en un negocio donde participan grupos de cirujanos plásticos, así como dermatólogos, oftalmólogos, odontólogos, nutricionistas, entrenadores físicos y otros sectores de la estética que hacen una economía robusta. En un foro sobre estos temas a mediados de agosto pasado en Me- dellín se dijo, según Héctor Rincón en el texto citado, con muy buena documentación, que en plata contante y sonante esta religión, que puede llamarse "proyecto imperio corporal", ha consolidado un movimiento de dinero que va en cuarto puesto después de las armas, de las drogas ilícitas y de las drogas farmacéuticas. Basta mirar el entorno para ver esa feligresía en quirófanos o en parques que va por la vida fingiendo que está buscando salud, y que consume todo lo que le venden a ver si encuentran el ideal de una belleza esquiva y de un cuerpo deslumbrante. Una feligresía que ahora reza por el cuerpo a bordo de una máquina estática o de una sala de cirugía, dirigida por un sacerdote que les tiraniza con un bisturí o con un megáfono " $\mathrm{y}$ a quien le agradecen cada sesión lo hermoso que le está quedando el cuerpo. Esa feligresía, esa, a la que ya el alma dejó de importarle porque no se ve", bien dice el mismo Rincón.

Lo malo es que las mencionadas y reiteradas cirugías, sin son ni ton, exponen a los seres humanos a un riesgo quirúrgico innecesario, que algunas veces ha terminado en muerte. Todo por unos dos o tres kilos de más.

También están de moda decenas de dietas de todos los pelambres y sabores. Ya estamos viendo los estragos de estas prácticas y de este culto narcisista por la delgadez extrema, en la salud de estas mujeres que han decidido sacrificar su vida para pulir un cuerpo, parafraseando la famosa poesía, Leyendo a Silva, de Guillermo Valencia. - Esto demuestra que la belleza no es algo absoluto e inmutable, sino que adopta distintas caras, según la época, el imperio dominante y la voracidad de los medios masivos de información. Hace falta repetir que no existe un solo ideal de belleza humana. Que, como lo demuestra la historia del arte, la belleza física está presente en una amplia gama de figuras y perfiles. Tan atractiva puede ser una pálida y alta rubia boreal, como una mulata rellenita y vivaracha. La hermosura exterior es apenas una parte, a veces la menos importante, del ser humano. Hay muchos otros rasgos fundamentales para triunfar en la vida, para la felicidad personal y para el éxito social, que no dependen de la balanza de pesos. Como escribió Henry David Thoreau: "La belleza no está aquí ni allá, ni en Roma ni en Atenas, sino dondequiera que encontremos un espíritu admirable" (1998). Además, el que no lleva la belleza dentro del alma, no la encontrará en ninguna parte, como bien lo deja entrever el libro El ingenioso hidalgo don Quijote de la Mancha.

\section{Comunicación, cultura y educación popular}

"Nuestras representaciones del mundo social están en su mayoría construidas por imágenes mediáticas porque no podemos vivenciar directamente a través de las experiencias el conjunto de acontecimientos, instituciones 
y hasta artefactos creados socialmente. La comprensión del mundo queda entonces vinculada en buena parte a las imágenes que nos hacemos de lo otro y de los otros" (Miralles, 2003, 10). El peligro que esto encierra es el de la simplificación de la complejidad de la realidad, y la escuela, el colegio y la universidad deberían tener en su repertorio estrategias para hacer frente al problema de los perversos estereotipos culturales y consumistas que se construyen desde temprano en la mente de los seres humanos. Las posibilidades para la consolidación del sentido crítico deben preservarse de los lugares comúnmente aceptados.

La construcción de las imágenes del mundo es fundamental entonces en la configuración de los aprendizajes propios del sistema educativo formal y de las llamadas virtudes cívicas y políticas. ¿Qué aprender? Si algo está claro hoy es que aprender no se limita a la instrucción escolar o universitaria, sino que se refiere a la incorporación de unos insumos para moverse en el mundo. En este sentido, imágenes fragmentarias y confusas sobre la belleza, sobre el cuerpo, sobre la verdad, campean alegre y livianamente en los medios de comunicación y son incorporados con algunos matices por lectores, televidentes y oyentes.

Varios expertos han llamado la atención sobre la incapacidad del discurso periodístico para tratar temas estructurales y de larga duración como la belleza del cuerpo, la pobreza y la riqueza. "Todo lo que trasciende el breve período de tiempo de la espectacularidad y la novedad mediática está condenado a desaparecer del repertorio de temas tratados en la comunicación" (Ibid).

Hoy, afrontamos la paradoja de vivir en un mundo con mucha información, pero seguimos estando mal informados. Hay que decir como decían Lippmann o Sartori: "La calidad de la información que recibe el ciudadano promedio es pésima”. Jesús Martín Barbero, García Canclini y muchos otros han hablado de otro tipo de alfabetización en el entorno más amplio de la sociedad y con los medios de comunicación porque la sola información no produce necesariamente conocimiento. En ese sentido es urgente pensar en la revisión de los modelos pedagógicos verticales, y en el aprovechamiento democrático de la reubicación de los conocimientos propios del colegio o la universidad en el contexto social.

Los educadores debemos, por tanto, bregar por una comprensión de los sistemas simbólicos que en nuestros espacios de trabajo se generan: reconocer cuál es el sentido de los educandos, desde dónde se expresan, con qué valores, qué significado asignan al tiempo y al espacio, cuáles son sus fronteras y cómo hacen uso de ellas. Esto de por sí nos obliga, según Alfonso Torres, a conocer el drama de la cotidianidad y las técnicas permanentes de los sujetos sociales y colectivos que usan los elementos de la cultura dominante desde su propia cultura: lo que hace la gente con la información de un noticiero, con las películas de Hollywood o con el reaggeton. Es decir, debemos entender la cultura como un camaleón mental, sentimental y estético que varía sus colores según las comunidades en las que se manifiesta.

Lo anterior nos lleva a confirmar que la cultura, en cuanto espacio central de la comunicación, no es un eje secundario sino esencial, pues ella es un generador continuo de sentidos, según unas estructuras materiales y emocionales dadas. Desde esta perspectiva, la comunicación no se configura de simples medios o recursos, sino de sentido; esto es, de modelos culturales que conducen a establecer relaciones, comportamientos, creencias, aspiraciones determinadas, que a su vez inducen a configurar ciertos usos de las cosas y, desde luego, ciertos hábitos. El aspecto comunicativo nos conduce, por tanto, a un nuevo sentido para la vida y para la historia.

"El típico hombre moderno tiene ojos y no observa, oídos y no escucha, corazón y no siente, razón y no piensa, ingenio y no crea. Ha renunciado a ser hombre" (Suárez Díaz, 1982, 123). Necesitamos una educación que se sintonice con esta grave situación y con la nociva nueva religión del imperio corporal. Afrontamos la paradoja de vivir en un mundo con mucha información manipulada y por eso estamos tan manejados. En este contexto, como profesor de Taller de Lenguajes del PCLEF, pienso que "el desafio primordial es hacer posible la comunicación, entendida como una dimensión de la vida que incluye - pero también trasciende- los medios y que, por eso mismo, no puede ser reducida a la existencia de unas tecnologías ni identificadas únicamente con unos procesos de información y de significación... Esta... supone la participación activa dialogal como condición indispensable para no quedarse únicamente en los niveles de la información o de la expresión simbólica" (Jaime Pérez, 1992, 6).

Pensamos que esta concepción comunicativa sólo es posible encontrarla en la educación popular, la cual concebimos como una alternativa pedagógica que permite verdaderamente la formación integral de hombres y mujeres. Este tipo de educación es un proceso intencional y organizado mediante el cual se facilita a los diferentes sujetos colectivos e individuales la apropiación, la recreación y la construcción del conocimiento, las destrezas y los afectos. Esto requiere meterse siempre en los esquemas de significación que los diferentes sujetos tienen. Requiere siempre, también, lo nuevo, nuevas preguntas, problemas, nuevas perspectivas. De este modo, la educación popular es una práctica social atravesada por los medios masivos de información, la cultu$\mathrm{ra}, \mathrm{y}$ a la vez influida por las exigencias económicas, las relaciones sociales y los intereses políticos y cotidianos 
de las clases dirigentes. Este modelo pedagógico alternativo necesita de la fuerza motivadora y productiva de la disputa y de la lucha discursiva. A este paradigma debe acceder lo inesperado, lo insospechado, un pensamiento nuevo, una nueva ocurrencia. Así, este tipo de educación se perfila como el saber teórico-práctico generado por los educadores populares y su comunidad a través de la reflexión individual y colectiva sobre la propia práctica a partir de la experiencia y de los aportes de otras prácticas y disciplinas que se intersecan con su quehacer.

La educación popular será manantial humano en la medida en que vaya lográndose la participación dialógica, en la cual todos los sujetos que interactúan puedan expresarse libre y creativamente, confrontando en forma constructiva opiniones y propuestas. Dentro de este

\section{Bibliografía}

ECO, Umberto (2005). Historia de la belleza, España, Lumen.

EL TIEMPO (2005). Editorial: Morir de belleza. Bogotá, abril 10, p. 22 A.

FERNÁNDEZ, Carlos F. (2005). De sapos a príncipes: otro triunfo del mercado, El Tiempo, Bogotá, 31 de julio, cuadernillo 1, p. 3.

GAVIRIA, Alejandro (2005). La ciencia de la silicona, En El Espectador, Bogotá, semana del 21 al 27 de agosto, p. 17 A.

JAIME PÉREZ, Gabriel (1992). Desafios de los Medios de Comunicación a la familia que se prepara para el tercer milenio, En revista Signo y Pensamiento No. 21, p. 6. Bogotá, Facultad de Comunicación Social, Pontificia Universidad Javeriana.

KRISTOF, Nicholas D. (2004). Construcción de mejores cuerpos, En El Espectador, Bogotá, agosto 29, p. 12 A. humanismo, los educadores populares escogemos la libertad, la entrega, la honradez y la bondad como príncipios dadores de sentido y dirección a la existencia. En esta educación está la cultura del cambio y del respeto a la vida y a la gente. Ella busca construir organización popular porque lo popular está hecho para mostrar lo que niega el capitalismo mediante la nueva religión del imperio corporal. La educación popular reivindica la libertad, la justicia, la igualdad y la democracia plena; es una alternativa pedagógica que mira de manera diferente a los distintos sujetos que intervienen en el proceso educativo: he ahí las energías espirituales de esta educación. Sólo con ellas los educadores podemos quebrarle el espinazo a la nueva religión del imperio corporal que tantos tormentos y vapuleos está causando a la gente de hoy.

MIRALLES CASTELLANOS, Ana María (2003). Educación, cultura y comunicación, En Caja de herramientas, p. 10, agosto, Bogotá.

MOLANO BRAVO, Alfredo (2004). Perchas, En El Espectador, Bogotá, septiembre 1, p. 16 A.

SILVA, Armando (2004). Arte e imaginarios globales, En Lecturas Fin de Semana, de El Tiempo, Bogotá, noviembre 13, p. 9

RINCÓN, Héctor (2005). El reinado del cuerpo, En revista Cambio, Bogotá, agosto 22, p. 88.

SUÁREZ DÎAZ, Reinaldo (1982). La educación: su filosofia, su psicologia, su método, México, Trillas, p. 133.

THOREAU, Henry David (1998). Sobre la desobediencia civil, Bogotá. Norma. 